\title{
Digital Literacy in Early Childhood
}

Servet Kardeș, Van Yüzüncü Yıl Üniversitesi Eğitim Fakültesi, ORCID ID: 0000-0002-4230-6628

\begin{abstract}
Digital literacy is one of the most important skills of the 21st century that is necessary for individuals to access the right information easily, quickly and effectively. The aim of this study is to reveal the views of preschool teachers about digital literacy to children. Case study design, one of the qualitative research methods, was used in the study. The research was carried out with the data collected through semi-structured interview form with 20 teachers who were reached by snowball sampling method in a province in eastern Anatolia. Content analysis method was used in data analysis. As a result, preschool teachers stated that digital literacy is beneficial, contributes to the development of the child, and digital literacy education should be given. There were also teachers who stated that digital materials should not be in preschool education. It was stated that social environment should be created for children to use safe digital devices, content control should be increased, children should play games and children should read books. As a suggestion, digital literacy education can be suggested to children, teachers and families in order to obtain information more reliably, easily and quickly in the digital age.
\end{abstract}

Keywords: Early childhood, preschool, media, digital literacy, preschool teacher

\section{İnönü University}

Journal of the Faculty of Education

Vol 21, No 2, 2020

pp. $827-839$

DOI: 10.17679/inuefd.665327

Article type:

Research article

\section{Suggested Citation}

Kardeş, S. (2020). Digital literacy in early chilhood, Inonu University Journal of the Faculty of Education, 21(2), 827-839. DOI: 10.17679/inuefd.665327 


\section{EXTENDED ABSTRACT}

\section{Introduction}

Digital literacy can be defined as perceiving, analyzing, evaluating the publications and messages given by written and visual mass media, and providing the individual with the ability to send appropriate messages to this process (Potter, 2013). With the increase in mass media, information and messages transmitted to individuals through these channels increased. Increased transmission of information and messages led to information pollution (O'Keeffe \& Clarke-Pearson, 2011). Media and mass media is a process in which the information to be presented to the individual is designed in advance and the message intended to be given to the individual is planned. In this process, the individual cannot think freely and becomes a passive recipient (Avcl, 2010).

Children are the most vulnerable group because they are more optimistic, more open to innovation and more curious than adults. Because of children spend long hours on TV and the Internet, TV and the Internet are becoming the only source of information for children. The use of the Internet also gives children the opportunity to communicate with the outside world and access information freely. At the same time, when used correctly, digital tools can motivate children to read, have fun and learn (Gillen, Arnott, Marsh, Bus, Castro, Dardanou \& Holloway, 2018). However, children are not aware of the damages of the internet and TV, being open to all kinds of information, and advertising and harmful consumption habits. As the use of media increases in developed countries, it is seen that children tend to be violent and obesity becomes a problem as a result of wrong eating habits. Also it is seen that increased sexual neglect and abuse; and unsafe information about sexuality (Gigli, 2004).

It is the responsibility of educational institutions and teachers to protect children from the harmful effects of the media and to make them conscious consumers of the media. Children need guidance in order to improve the healthy development of early childhood children, to increase their awareness of digital literacy and to contribute to their academic success. It is very important for the teacher to be a good digital literate, to adapt the digital instruments to the curriculum and to use them appropriately in the classroom (Gillen \& Kucirkova, 2017). Therefore, it is very important that teachers raise awareness of media literacy and educate children in the classroom about the positive and negative effects of the media. In this case, teachers' awareness of the harmful effects of media tools and what children think about digital media habits gain importance.

\section{Purpose}

In this study, it is aimed to reveal pre-school teachers' digital media awareness and thoughts about children's digital media habits. For this purpose, the following questions have been identified.

1. What are the opinions of preschool teachers about digital literacy?

2. What is technology addiction in children according to preschool teachers?

\section{Method}

This research is a qualitative study of preschool teachers' knowledge and awareness about digital literacy. In this study, it is thought that the case study design is suitable for the purpose of this study since it is aimed to describe in depth the views of preschool teachers about digital literacy. The study group consists of 20 pre-school teachers in a province in the Eastern Anatolia region. Snowball sampling method, one of the purposeful sampling methods, was used in the study. In the research, semi-structured interview form developed by the researcher was used as data collection tool. Content analysis method was used in the analysis of the data obtained in the study. By means of content analysis method, the data is analyzed in depth and relations and concepts are tried to be revealed (Yıldırım ve Şimşek, 2013).

\section{Findings}

preschool teachers stated that digital literacy is beneficial, contributes to the development of the child, and digital literacy education should be given. There were also teachers who stated that digital materials should not be in preschool education. It was stated that social environment should be created for children to use safe digital devices, content control should be increased, children should play games and children should read books. 


\section{Discussion \& Conclusion}

As a result of the research, it is seen that the role of digital literacy in early childhood education, digital literacy education, benefits of digital literacy, technology dependence and control of digital contents come to the fore. Concretizing knowledge, using multiple resources in accessing information, supporting education with visuals, providing easy, fast and economic access to information are seen as the role of digital literacy in education. Similarly, Karabacak and Sezgin (2019) stated in their research that there is a digital transformation in the field of education and for this transformation, the courses and practices that will increase digital literacy should be accelerated. Inmeideh \& Alkhawaldeh (2017) stated that children need a rich digital literacy program in the digital age. Gillen, Arnott, Marsh, Bus, Castro, Dardanou \& Holloway (2018) concluded that digital media offers innovative learning experiences to children. As a result of the research, teachers stated that technology related trainings should be given and families should be supported with technology seminars. Donohue (2014) concluded that teachers and families need to develop digital literacy skills in order to provide good guidance to their children

As a suggestion, digital literacy education can be offered to children, teachers and families in order to obtain information more reliably, easily and quickly in the digital age. Further, it is advisable to present a qualified social environment to the child, to guide the use of technology and to increase the content controls in the use of technology in order to prevent the child from being addicted to technology and to avoid any harm that may arise from it. 


\title{
Erken Çocukluk Döneminde Dijital Okuryazarlık
}

\author{
Servet Kardeş, Van Yüzüncü Yıl Üniversitesi Eğitim Fakültesi, ORCID ID: 0000-0002-4230-6628
}

Öz

Dijital okuryazarlık 21. yy becerileri arasında yer alan, bireylerin doğru bilgiye kolay, hızlı ve etkili bir şekilde ulaşması için gerekli olan çağın en önemli becerilerinden biridir. Bu araştırmanın amacı okul öncesi ögretmenlerinin dijital okuryazarlık ile ilgili görüşlerini ortaya koymaktır. Araştırmada nitel araştırma yöntemlerinden durum çalışması deseni kullanılmıştır. Araştırma doğu Anadolu bölgesinde bulunan bir ilde kartopu örnekleme yöntemiyle ulaşılan 20 ögretmenle yarı yapılandırılmış görüşme formu aracilığyla toplanan verilerle gerçekleştirilmiştir. Verilerin analizinde içerik analizi yöntemi kullanulmıştır. Sonuç olarak okul öncesi öğretmenleri, dijital okuryazarlığın faydalı olduğu, çocuğun gelişimine katkıda bulunduğu, dijital okuryazarlık eğitimlerinin verilmesi gerektiğini ifade etmiştir. Dijital materyallerin okul öncesi eğitimde olmaması gerektiğini ifade eden ögretmenler de olmuştur. Güvenli dijital alet kullanımı için çocuklara sosyal çevre oluşturulması gerektiği, içerik denetimlerinin arttırlması, çocukla oyun oynama ve çocukla kitap okuma gerektiği ifade edilmiştir. Öneri olarak dijital çağda bilginin daha güvenilir, kolay ve hızlı elde edilmesi için çocuklara, ögretmenlere ve ailelere dïital okuryazarlık eğitimi verilmesi önerilebilir.

Anahtar Kelimeler: Erken çocukluk, okul öncesi, medya, dijital okuryazarlık, okul öncesi öğretmeni

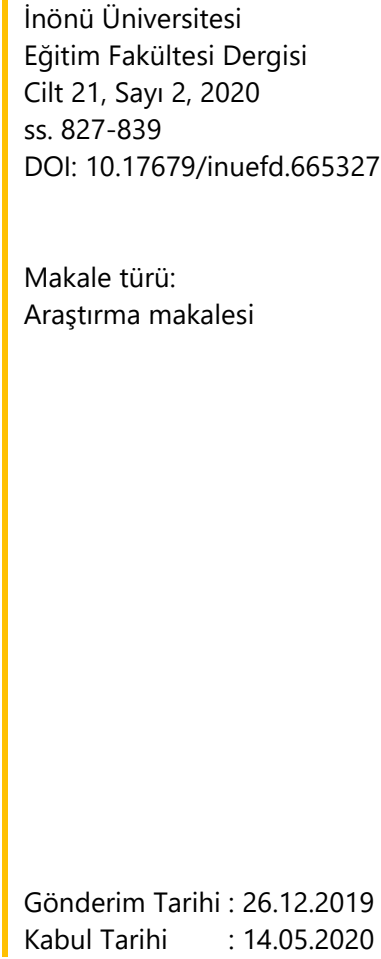

\section{Önerilen Atıf}

Kardeş, S. (2020). Erken çocukluk döneminde dijital okuryazarlık. Inönü Üniversitesi Eğitim Fakültesi Dergisi, 21(2), 827839. DOI: $10.17679 /$ inuefd. 665327 


\section{Giriş}

Dijital okuryazarlık yazılı ve görsel kitle iletişim araçları tarafından verilen yayın ve iletilerin algılanması, çözümlenmesi, değerlendirilmesi ve bu sürece uygun ileti gönderilmesi kabiliyetinin bireye kazandırılması olarak ifade edilebilir (Potter, 2013). Kitle iletişim araçlarının artmasıyla birlikte bu kanallar aracilığıla bireye iletilen bilgi ve mesajlarda artmıştır. Iletilen bilgi ve mesajların artışı beraberinde bilgi kirliliğini de getirmiştir (O'Keeffe \& Clarke-Pearson, 2011). Medya ve kitle iletişim araçları daha önceden kurgulanmış ve bireye sunulacak bilgilerin önceden tasarlandığı, bireye verilmek istenen mesajın planlandığı bir süreçtir. Bu süreçte birey özgür düşünememekte pasif alıcı durumda olmaktadır (Avcı, 2010).

Dijital araçlarla medyada ulaştığımız birçok bilgi önyargılı, eksik, yanlış yönlendirme içeren ya da yanlışıklarla dolu bilgilerden oluşabilmektedir. Özellikle internet büyük bir bilgi kirliliği içermektedir. Bu bilgi kirliliğinin içerisinde doğru bilgiye ulaşmak gerekir. Çocuklarımızın yeme içme alışkanlıkları, sigara ya da alkol kullanımı, cinsel tercihleri, öfke ve şiddetle başa çıkma yöntemleri TV ve diğer medya araçları yoluyla elde ettikleri bilgiler tarafından önemli oranda etkilenmektedir. Dijital aletlerin bilinçli kullanımı sadece yüzeysel alanlarda bilinçli olmayı sağlamaz aynı zamanda yüzeysel olanın altında medya araçlarının vermeye çalışığı derin anlamları da analiz etmemizi sağlar. Dijital okuryazarlık becerisi problem çözme, araştırma, beceri kazanımı, iş birlikli öğrenme sosyal etkileşim ve eleştirel beceri yeteneği kazandırır (Gillen, Arnott, Marsh, Bus, Castro, Dardanou \& Holloway, 2018)

Dünyanın her yerinde çocuklar hemen hemen aynı özellikleri sergilemektedirler. Çocuklar temel olarak yetişkinlere göre daha iyimser, yeniliklere daha açık ve daha merakı bireyler oldukları için zararlı etkilere en açı ve en korunmasız grubu oluşturmaktadır. Çocuklar TV, telefon ve tablet önünde uzun saatler harcarsa bu aletler çocuklar için yegâne bilgi kaynağı haline gelebilmektedir. Internet kullanımı ise çocuklara dış dünyayla iletişim haline geçmesi ve özgürce bilgiye ulaşma fırsatı tanıdığı için çocuklara çok cazip ve çekici gelmektedir. Bununla birlikte dijital araçlar doğru kullanıldığında çocukları okumaya, eğlenmeye ve öğrenmeye motive edebilir (Gillen, Arnott, Marsh, Bus, Castro, Dardanou ve Holloway, 2018). Fakat çocukların internetin ve TV'nun zararlarının farkında olmaması, her türlü bilgiye açık olması ve reklamlarla zararlı tüketim alışkanlıklarının çocuğa kazandıııması çocuğa zarar vermektedir. Gelişmiş ülkelerde çocukların medya kullanımı arttıkça şiddet eğilimi gösterdiği, yanlış beslenme alışkanlıkları sonucu obezitenin bir sorun haline geldiği, cinsel ihmal ve istismarın arttığı ve cinsellik hakkında güvenli olmayan bilgilerin çocuklarda yaygınlaştığı görülmektedir (Cantor \& Wilson, 2003; Donnerstein \& Linz, 1986; Peterson \& Densley, 2017). Bu sorunların temelinde ise güvensiz ve kontrolsüz bir medya ağının olduğu söylenebilir (Gigli, 2004).

Çocuğun eğitimi ve denetimi üzerinde aile, okul, toplum etkisini yitirmektedir. Kontrolsüz medya kullanımı gittikçe artan bir şekilde çocuğun kişiliği ve aidiyeti üzerinde olumsuz etki sahibi olmaktadır. Medya çocukları bireyselliğe itmekte ve birlikte hareket etme, toplumun bir ferdi olma, aidiyet duygularına zarar vermektedir (Gigli, 2004). Medyanın olumsuz etkileri sonucu çocukların okul performansı düşmekte, akranlarına yönelik şiddet sergilemekte, iletişiminde öfke ve stres öne çıkmakta, bozuk yeme alışkanlıkları geliştirmekte ve kâbuslar görmektedir (Villani, 2001). Bilinçsiz ve yanlıs medya kullanımı ve dijital alışanlıklar hızla büyüyen sosyal ve toplumsal problemleri de beraberinde getirmektedir. Medyanın oluşturduğu olumsuzluklardan dolayı geleceğimiz olan çocuklar için tehlike çanları çalmakta ve bu çocuklarımızın büyük oranda zararlı içeriğe sahip devasa medya sektörüne karşı korunması ve bilinçlendirilmesi gerekmektedir. Bu bilinci oluşturma ve koruma görevi ailelerle birlikte eğitim kurumlarındadır (Livingstone, 2007). Bütün bu olumsuz etkilerin önüne geçmek için erken çocukluk dönemindeki öğretmenler ve çocuklarının dijital medya hakkında bilinçlendirilmesi gerekmektedir.

Erken çocukluk dönemindeki çocuklar gerçeklik ile kurguyu birbirinden ayıramadıkları için TV da çıkan zararlı içerikli yayınlar çocukların ruh hali üzerinde olumsuz etkiler bırakmaktadır. Çocuklar 1,5-2 yaş civarlarında TV izlemeye başlamakta ve günlük gittikçe artan saatlerde TV izleme alışkanlığı edinmektedirler. Erken çocukluk dönemindeki çocukların okul dışında en fazla vakitlerini TV izlemek almaktadır. Uzun süre TV izlemenin uyku, dikkat ve kişilerarası ilişkiler üzerinde olumsuz etkileri vardır (Jolin \& Weller, 2011). Çocuğun görsel, işitsel ve yazılı medyanın zararlı etkilerinden korunması için erken çocukluk döneminden itibaren medyanın zararlı etkilerinin farkındalığını kazanması gerekmektedir (Büyükbaykal, 2007; Coşkun ve Arslantaş, 2016; Kuula, Kuusisto \& Seisto, 2014).

Zengin uyarıcılı ortamda yaşayan, akranları ve yetişkinlerle iyi iletişim içerisinde olan çocuklar diğer çocuklara göre medyanın olumsuz etkilerine daha az maruz kalmaktadırlar (Buckingham, Banaji, Carr, Cranmer \& Willett, 2005). Öğretmenler ve aileler çocuklarla birlikte dijital medyayı kullanmalı, dijital medyanın doğru kullanımı hakkında çocuklarıyla sohbet etmelidirler. Çocuğun medya ve iletişim araçlarını kullanımında bazı kurallar koymalıdırlar (Nathanson \& Cantor, 2000). 
Dijital okuryazarlık konusunda eğitim kurumlarının, öğretmenlerin ve çocukların algıları ve bilinç düzeyleriyle ilgili çeşitli çalışmalar yapılmıştır. Temel, Kostak ve Çelikkalp (2014) yaptıkları çalışmada erken çocukluk dönemine yönelik çizgi filmlerin özellikle fiziksel şiddet olmak üzere büyük oranda şiddet içerikli olduğu sonucuna ulaşmıştır. Çocukların bu şiddetten korunması içinde ailelerin şiddet ve etkisi hakkında bilinçlendirilmesi için ailelere eğitimler verilmesi önerisinde bulunmuştur (Temel, Kostak ve Çelikkalp, 2014). Doğan ve Göker (2012) yaptıkları araştırmada çocuklar TV izlemek yerine ailelerinin derslerine yardımcı olmasını, birlikte kitap okumayı ya da gündelik olaylarla ilgili sohbet etmeyi istemişlerdir. Ailelerin bu yönlü bir yaklaşımı olmadığı için çocuklar TV ekranlarına mahkûm olmaktadırlar. Dolayısıyla ailelerin eğitilmesi gerektiğini ifade etmiş ve bu yönde eğitimlerin gerçekleştirilmesini önermişlerdir. Tahiroğlu, Çelik, Bahalı ve Avcı (2010) yaptıkları araştırmada internette oyun oynamanın ve kontrolsüz bir şekilde dolaşmanın internet bağımlılığının en önemli nedenleri olduğunu görmüşlerdir. Dikkat eksikliği ve hiperaktivite bozukluğu, kaygı bozuklukları ve anti sosyal davranışların internet bağımlılığına sıklıkla eşlik ettiği sonucu çıkmıştır. Bu sorunların ve bağımlılığın önlenmesi için ailelerin ve öğretmenlerin medya kullanımı konusunda bilgilendirilmesi ve yasal düzenlemelerin çıkarılmasını tavsiye etmişlerdir.

Eğitimcilerin dijital okuryazarlık farkındalığı hakkındaki çalışmalara baktığımızda Koçyiğit, Gündoğdu ve Bay (2010) yaptıkları araştırmada, okul öncesi öğretmen adayları gündelik hayatta şiddetin ortaya çıkmasında en fazla etki bırakan öğelerin medya ve teknoloji olduğunu ifade etmişlerdir. Curran \& Hyman (2000) yaptıkları araştırmada 8 yaşından büyük çocuklar arasında internette ve televizyonda satılan ürünler ve reklamları konusunda gittikçe artan bir bilinçlenme olmasına rağmen aynı durumun 8 yaşın altındaki çocuklar için geçerli olmadığı sonucuna ulaşmıştır. Yaşları büyük çocukların internete girdikleri reklam sitelerinin reklam içerikli olduğunun farkında olduğu ancak küçük çocukların bu durumun farkında olmadıkları sonucuna ulaşmıştır. Son olarak VanderBorght \& Jaswal (2009) yaptıkları araştırmada çocukların televizyon izleme oranları arttıkça, televizyonda gördükleri olayların dünyayı temsil ettiğini düşünme oranlarının da arttığı sonucuna ulaşmışlardır. Ayrıca ailelerin çocuklarını kritik düşünmeye ve sorgulamaya sevk ettikçe çocukların televizyonda gördüğü her şeyi kabul etme oranları da düşmektedir.

İlgili araştırmaların bütününe baktığımızda özellikle erken çocukluk dönemindeki çocukların bilinçli bir medya tüketicisi olmadıkları ve medya araçlarının her türlü zararlı etkilerine açık oldukları sonucu çıkarılabilir. Somut düşünme becerisi kazanamayan, doğru ve yanlışı ayırt etme algısını tam olarak kazanamamış, reklam ve ticari ürünleri ayırt edemeyen çocuklar medyanın zararlı etkilerine açık olacaktır. Çalışmalar çocukların bilinçli birer medya tüketicisi olmaları ve medyanın zararlı etkilerinden korunmaları için öğretmenlere dijital okuryazarlık eğitimi verilmesi gerektiği ve bu konuda bilinçlenmeleri gerektiğini göstermektedir (Donohue, 2014; Gillen, Arnott, Marsh, Bus, Castro, Dardanou \& Holloway, 2018; Gillen \& Kucirkova, 2017). Ayrıca öğretmenlerin dijital okuryazarlık konusunda farkındalıklarının arttırılması ve eğitilmeleri çocukların medyanın zararlı etkilerinden korunması için önem oluşturmaktadır. Çünkü medya ve çağımızdaki dönüşüm ve gelişmelere uyum sağlamak için dijital okuryazar olmak gerekir.

\section{Araştırmanın önemi ve amacı}

Çocukların medyanın zararlı etkilerinden korunması ve bilinçli birer medya tüketicisi olması için eğitim kurumları ve öğretmenlerin sorumluluğu bulunmaktadır. Erken çocukluk dönemindeki çocukların sağlıklı gelişimi, dijital okuryazarlık konusundaki farkındalık düzeylerinin arttırılması ve akademik başarılarına katkıda bulunmak için çocukların iyi bir rehberliğe ihtiyacı bulunmaktadır. Öğretmenin iyi bir dijital okuryazar olması, dijital aletleri müfredata uyumlu hale getirmesi ve sınıf ortamında uygun kullanımı çocukların sağlıklı gelişimi açısından oldukça önemlidir (Gillen \& Kucirkova, 2017). Bu yüzden öğretmenlerin medya okuryazarlığı farkındalığının ortaya konulması ve sınıftaki çocukları medyanın olumlu, olumsuz etkileri konusunda eğitmeleri oldukça önemlidir. Bu durumda öğretmenlerin medya araçlarının zararlı etkileri konusunda farkındalıkları ve çocukların dijital medya alışkanlıkları konusunda ne düşündükleri önem kazanmaktadır.

$\mathrm{Bu}$ araştırmada okul öncesi öğretmenlerinin dijital medya farkındalıkları ve çocukların dijital medya alışkanlıkları ile ilgili düşüncelerinin ortaya konulması amaçlanmıştır. Bu amaç doğrultusunda aşağıdaki sorular belirlenmiştir.

1. Okul öncesi öğretmenlerinin dijital okuryazarlıkla ilgili görüşleri nelerdir?

2. Okul öncesi öğretmenlerine göre dijital okuryazarlığın faydaları nelerdir?

3. Okul öncesi öğretmenlerine göre çocuklarda teknoloji bağımlılığı nasıldır? 


\section{YÖNTEM}

\section{Araştırmanın Deseni}

Bu araştırma okul öncesi öğretmenlerinin dijital okuryazarlık ile ilgili bilgi ve farkındalıklarına yönelik nitel bir çalışmadır. Nitel araştırma, araştırmaya katılan bireylerin bakış açılarının ortaya konulmasının amaçlandığı, olayın ya da durumun derinlemesine betimlenmesini sağlayan ve tümevarım yönteminin kullanıldığı araştırma türüdür (Miles \& Huberman, 1994). Bu çalışmada okul öncesi öğretmenlerinin dijital okuryazarlık hakkındaki görüşlerinin derinlemesine betimlenmesi amaçlandığı için durum çalışması deseninin bu çalışmanın amacına uygun olduğu düşünülmektedir.

\section{Çalışma Grubu}

Araştırmanın çalışma grubunu Doğu Anadolu bölgesinde bir ilde yer alan 20 okul öncesi öğretmeni oluşturmaktadır. Araştırmada amaçlı örneklem yöntemlerinden kartopu örneklem yöntemi kullanılmıştır. Bu yöntem, çalışmada yer alacak katılımcılara birbiriyle ilişkili olan ve araştırmada katılımcı olan bireyler aracılığıyla ulaşmayı ve yeni bilgiler elde etmeyi sağlar (Patton, 2014). Okul öncesi öğretmenlerinin dijital okuryazarlığa ilişkin görüşlerini derinlemesine analiz etme amacıyla görüşülen öğretmenlerin 16'sı kadın 4'ü erkek öğretmenlerden oluşmaktadır. Öğretmenlerin 9'u 1-3 yıl arası mesleki deneyime sahip iken, 9'u 4-6 yıl mesleki deneyime sahip ve 2'si ise 7 ve üzeri yıl mesleki deneyime sahiptir. Öğretmenlerin 3'ü dijital okuryazarlık ile ilgili eğitim aldıklarını ifade ederken kalan 17 öğretmen bu konuda daha önce herhangi bir eğitim almadığını ifade etmiştir.

\section{Verilerin Toplanması}

Araştırmada veri toplama aracı olarak araştırmacı tarafından geliştirilen yapılandırılmamış görüşme formu kullanılmıştır. Görüşme formu geliştirilmeden önce konuyla ilgili alanyazın ayrıntılı bir şekilde araştırılmış ve dijital okuryazarlık ile ilgili daha önce geliştirilmiş ölçekler (Hamutoğlu, Güngören, Uyanık ve Erdoğan, 2017; Ocak ve Karakuş, 2018; Üstündağ, Güneş ve Bahçivan, 2017 ve çalışmalar (Acar, 2015; Onursoy, 2018; Özerbaş ve Kuralbayeva, 2018) araştırılmıştır. Daha sonra araştırmada elde edilmek istenen bilgiye uygun olarak 10 görüşme sorusu hazırlanmış ve bu görüşme soruları dil ve içerik bakımından kontrol edilmesi amacıyla alanda doktora derecesine sahip üç uzmana gönderilmiştir. Uzmanların dönütleri üzerine forma bir soru eklenmiş, 3 soru çıkarılmış ve bir soru üzerinde de ifade değişikliğine gidilmiştir. Yarı yapılandırılmış görüşme formunun son hali 8 sorudan oluşmuştur. Form son olarak anlaşılabilirlik ve amaçlara uygun bilgi elde edilip edilemeyeceğinin kontrolü için 2 okul öncesi öğretmene ön görüşme şeklinde uygulanmıştır. Görüşme formunda yer alan birkaç örnek soru şöyledir. 1) Dijital okuryazarlığın eğitimdeki rolü nedir? 2) Dijital okuryazarlık erken dönemdeki çocukların gelişimine ve öğrenmelerine ne gibi katkılar sunabilir? 3) Dijital okuryazar olmanın çocukların eğitiminde sağlayacağı avantajlar var mıdır? varsa nelerdir? 4) Çocuğun teknoloji kullanımında istenmeyen durumları (teknoloji bağımlılığı, sınırsız içerik erişimi vs) ortadan kaldırmak için ne gibi önlemler alınabilir? Sizin aldığınız önlemler nelerdir? Görüşme esnasında araştırmacı sorular anlaşılmadığında yönlendirme yapmadan ek açıklamalarda bulunmuştur. Okul öncesi öğretmenleriyle yapılan görüşmeler 20-25 dakika civarında sürmüştür. Bu araştırma, katılımcılara fiziksel ya da psikolojik zarar verme ihtimali olmayan bir araştırmadır. Katılımcıların özel hayatının gizliliği ve mahremiyetini koruma amaçlı ad soyad gibi bilgiler alınmamıştır. Okul öncesi öğretmenleriyle görüşmeden önce araştırmayla ilgili bilgi verilmiştir. Görüşmeden sonra elde edilen veriler görüşmecilerle paylaşılmış bir kez daha konuyla ilgili ifadeleri teyit ettirilmiştir. Araştırmada yararlanılan kaynaklar için metinde dipnot eklenmiş ve kaynaklar kısmında kullanılan kaynaklar belirtilmiştir.

\section{Verilerin Analizi}

Araştırmada elde edilen verilerin analizinde içerik analizi yöntemi kullanılmıştır. İçerik analizi yöntemi ile veriler derinlemesine analiz edilerek ilişkiler ve kavramlar ortaya konulmaya çalışılır (Yıldırım ve Şimşek, 2013). Bu araştırmada elde edilen verilerin içerik analizi sürecinde aşağıdaki sıralama izlenmiştir. Veri analizi sürecinde görüşmede kullanılan sorular ve elde edilen bilgiler veri analizi için temel oluşturmuştur. Görüşme sorularından elde edilen bilgiler ham veri olarak ortaya konulmuştur. Araştırma kapsamı dışında kalan ham veriler ayıklanmıştır. Kalan veriler derinlemesine incelenmiş ve ortaya kodlar çıkarılmıştır. Kodlar birbiriyle ilişkilerine göre sınıflandırılmıştır. Analiz sürecinde okul öncesi öğretmenlere (Ö1, ö2, ö3...) kodlar verilmiştir. Araştırmada katılımcı ifadelerinden doğrudan alıntılar verilmiştir. Araştırmada elde edilen verilerin analizinde güvenilirliği sağlamak için elde edilen veriler iki farklı uzman tarafından ayrı ayrı kodlanmış ve kodlayıcılar arası uyum yüzdesi hesaplanmıştır. Kodlayıcılar arası uyuma bakmak için Miles \& Huberman'ın (1994) ortaya koyduğu formül (Güvenirlik=Görüş birliği/görüş birliği+görüş ayrılığı) kullanılmış 
ve kodlayıcılar arası uyum \% 82 olarak hesaplanmıştır. Araştırmacıların farklı olarak değerlendirdikleri kodlar üzerinde de uzlaşmaya gidilmiştir.

\section{BULGULAR}

Okul öncesi öğretmenlerle yapılan görüşmelerden elde edilen verilere göre dijital okuryazarlık hakkındaki öğretmen görüşleri "dijital okuryazarlığın eğitimdeki rolü, erken çocuklukta dijital okuryazarlık eğitimi, dijital okuryazarlığın faydaları, çocuklarda teknoloji bağımlılı̆ını engelleme ve dijital içeriklerin denetimi" olmak üzere beş tema altında toplanmıştır. Belirlenen temalara dair öğretmen görüşleri aşağıda verilmiştir.

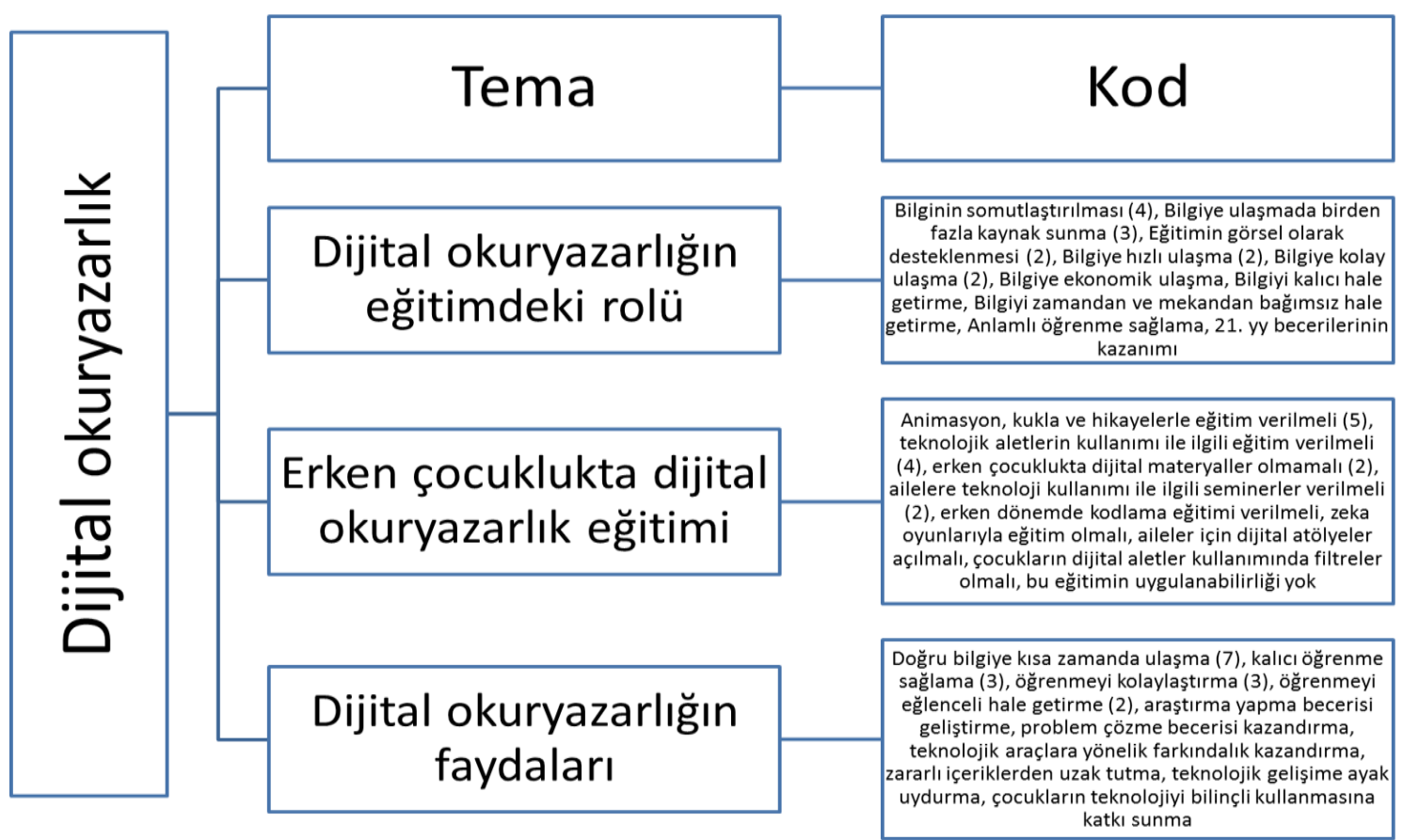

Şekil 1. Dijital okuryazarlığa ilişkin tema ve kodlar

Şekil 1.de görüldüğü gibi okul öncesi öğretmenleri, dijital okuryazarlığın bilginin somutlaştırılması, bilgiye ulaşmada birden fazla kaynak sunma, eğitimin görsel olarak desteklenmesi, bilgiye hızlı, kolay ve ekonomik ulaşım sağlama, anlamlı öğrenme ve 21. Yy becerilerinin kazanımı açısından faydalı olduğunu düşünmektedir. Öğretmenler erken çocuklukta dijital okuryazarlığın animasyon, kukla ve hikâyelerle kazandırılabileceğini söylemişlerdir. Teknolojik aletlerin kullanımı ile ilgili eğitimler verilmesi gerektiği, ailelere teknolojik aletlerin kullanımı ile ilgili seminerlerin verilmesi ve aileler için dijital atölyelerin olması gerektiği ifade edilmiştir. Çocuklar için filtrelerin olması, kodlama eğitimleri ve zekâ oyunlarının erken çocuklukta kullanılması öğretmenler tarafından dile getirilmiştir. Dijital okuryazarlığın faydalarına baktığımızda ise doğru bilgiye kısa zamanda ulaşma, kalıcı öğrenme sağlama, öğrenmeyi eğlenceli hale getirme ve araştırma yapma becerisi kazandırma öne çıkan görüşler olmuştur. Katılımcıların bazı görüşlerine ilişkin doğrudan alıntılar aşağıda verilmiştir.

"Bilgiye ulaşma yolunda dijital okuryazarlık çok önemlidir. lç̧inde bulunduğumuz bilgi çağında doğru bilgiye ulaşmak için önemli bir beceridir." Ö. 13.

"2023 eğitim vizyonunda 21. yy becerileri yer almaktadır. Bu becerilerin kazanılmasında teknolojinin payı büyüktür." Ö. 18.

"Eğitimde yaşanan dijital dönüşüm bilgiye zamandan ve mekandan bağımsı ulaşabilme imkanı vermiş ve eğitimi olumlu yönde etkilemiştir. Dijital ortam sayesinde daha fazla duyu organı işe koşularak daha anlamlı ve verimli öğrenmeler sağlanmaktadır." Ö. 19.

"Erken çocukluk döneminde telefon ve tabletlere yüklenen zeka oyunlarıyla çocukların erken yaşta zekalarının gelişimi desteklenebilir. Ancak teknolojik aletlerin bağımlıık yapmaması için kullanımı sınırlandırımalıdır." Ö.15. 
"Teknolojiyi doğru ve etkin kullanma konusunda çalışmalar yapılmalı. Teknolojik aletlerin olumsuz etkileri olabildiğince azaltılmalı." Ö.12.

"Erken Dijital okuryazarlık kolay, hızlı ve kalıcı öğrenme sağlar. Erken dönemde kodlama eğitiminin temel düzeyi öğretilebilir." Ö.4.

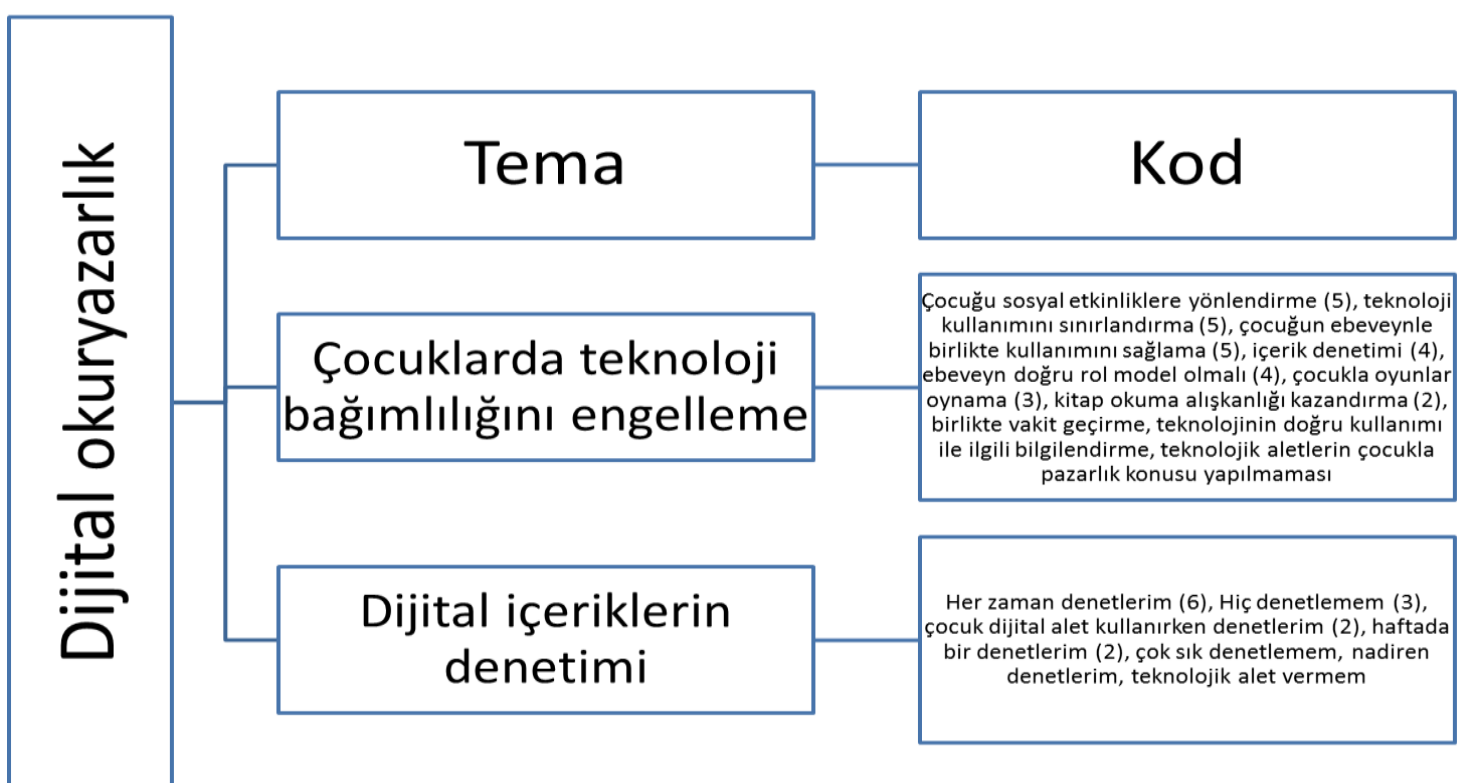

Şekil 2. Dijital okuryazarlığa ilişkin tema ve kodların devamı

Şekil 2'ye bakıldığında öğretmenler teknoloji bağımlılığını engellemek için çocuğun sosyal etkinliklere yönlendirilmesi, teknoloji kullanımının sınırlandırıması, içeriğin denetlenmesi ve teknolojik aletlerin yetişkin denetiminde kullanılması gerektiğini ifade etmişlerdir. Ebeveynlerin doğru rol model olması, çocuklarla birlikte vakit geçirmesi ve teknolojik aletlerin çocukla pazarlık konusu yapılmaması bağımlılığı engellemeye yönelik diğer öneriler olmuştur. Son olarak öğretmenlerin çoğunluğu çocuğun teknolojik alet kullanımında içeriği denetlediklerini ifade etmişlerdir. Buna rağmen bazı öğretmenler içeriği denetlemediğini ifade etmiş bir öğretmende teknolojik alet kullanımına izin vermediğini ifade etmiştir. Okul öncesi öğretmenlerinin doğrudan alıntılanan bazı ifadeleri aşağıdaki gibidir.

"Eğer çocuğun bağımlı olmasını istemiyorsak her ağladığında ya da her istediğinde eline tablet veya telefon verilip susturulmamalıdır. Kullanımda mutlaka sınırlamalar olmalıdır." Ö. 15.

"Çocuğun teknolojik aletlerle vakit geçirmesine çok fazla izin vermem. Teknoloji ile eğlenmeyi tek yol olarak sunmam. Kitap okuma alışkanlığı kazandırırım. Çocuklara farklı seçenekler veririm." Ö.3.

"Öncelikle kendi teknoloji kullanım alışkanlığımı gözden geçiririm. Süre kısıtlaması koyarak teknolojik aletleri kullanmasına izin veririm. Bu aletleri ortak alanlarda gözümün önünde kullanmasını sağlarım." Ö.19.

"Teknolojinin amaç değil bilgiye ulaşmada veya hayatı kolaylaştırmada araç olduğu kavratılırsa bu tarz bir bağımlılıktan söz edilemez." Ö. 13.

"Teknolojik aletler dışında çocukları eğlendirecek daha güzel alternatifler sunulabilir." Ö.9.

"Bir öğretmen olarak çocuğun eriştiği içeriği kontrol etmem. Ailesinin de sorumluluklarını bilmesi gerekir." Ö.7.

"Çocuk internete her girdiğinde hangi sitelere girdiğine, hangi oyunları oynadığına bakarım. Günümüzde çocukları intihara sürükleyen çok korkutucu oyunlar olduğu için sık sık denetlenmeli." Ö.5. 


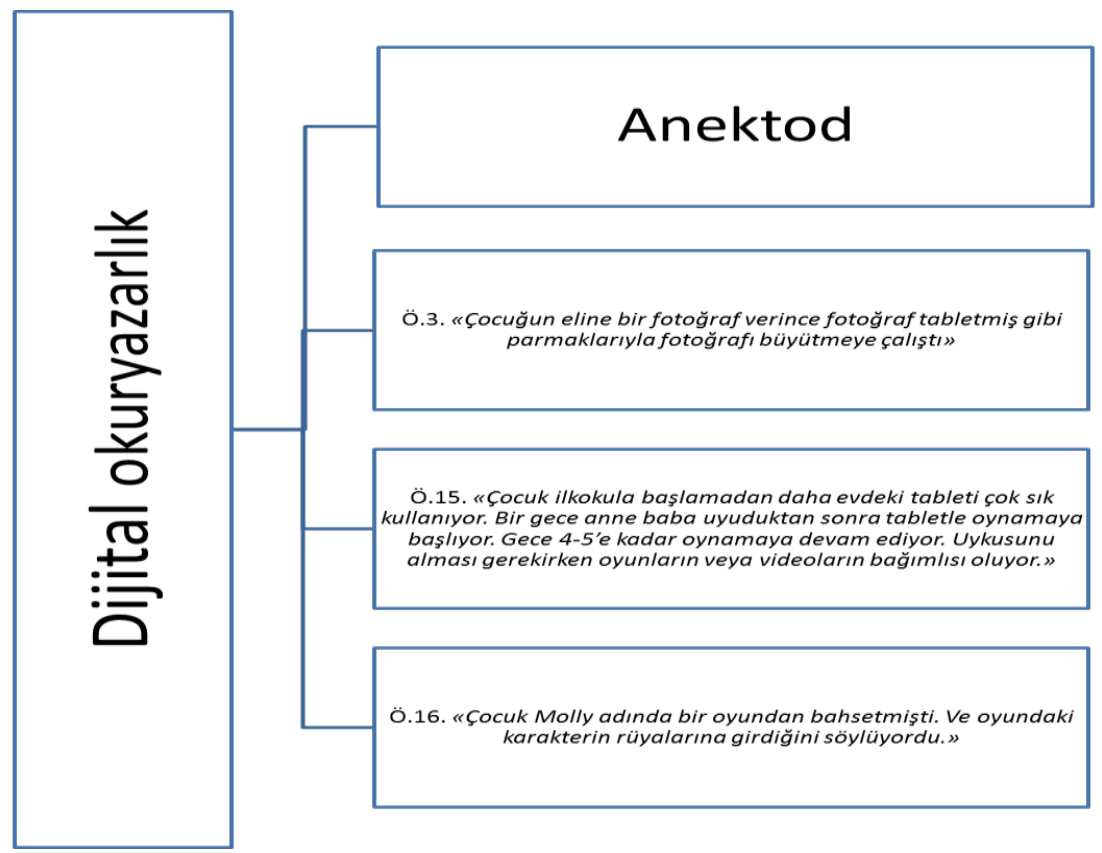

Şekil 3. Dijital okuryazalıkla ilgili anektodlar

Şekil 3'te görüldüğü gibi öğretmenlerin çocuklarla yaşadıkları bir anektodu paylaşmaları istenmiştir. Paylaşılan anektodlardan teknolojik aletlerin çocukların gelişimi üzerinde etkili olduğu ve çocuklar üzerinde bazı olumsuz etkileri olduğu görülmektedir.

\section{TARTIŞMA, SONUÇ VE ÖNERILER}

Araştırma sonucunda erken çocuklukta dijital okuryazarlığın eğitimdeki rolü, dijital okuryazarlık eğitimi, dijital okuryazarlığın faydaları, teknoloji bağımlılığı ve dijital içeriklerin denetiminin ön plana çıktığı görülmektedir. Bilginin somutlaştırılması, bilgiye ulaşmada birden fazla kaynak kullanma, eğitimin görsellerle desteklenmesi, bilgiye kolay, hızlı ve ekonomik ulaşım sağlama dijital okuryazarlığın eğitimdeki rolü olarak görülmüştür. Benzer olarak Karabacak ve Sezgin (2019) yaptıkları araştırmada eğitim alanında dijital bir dönüşümün olduğu ve bu dönüşüm için dijital okuryazarlığı arttıracak ders ve uygulamalara hız verilmesi gerektiğini ifade etmişlerdir. Ihmeideh \& Alkhawaldeh (2017) dijital çağda çocukların zengin bir dijital okuryazarlık programına ihtiyacı olduğunu ifade etmişlerdir. Gillen, Arnott, Marsh, Bus, Castro, Dardanou \& Holloway (2018) yaptıkları araştırmada dijital medyanın çocuklara yenilikçi öğrenme deneyimleri sunduğu sonucuna ulaşmışlardır. Araştırma sonucunda öğretmenler teknoloji ile ilgili eğitimlerin verilmesi gerektiği ayrıca ailelerin de teknoloji konulu seminerlerle desteklenmesi gerektiğini ifade etmişlerdir. Donohue (2014) öğretmen ve ailelerin çocuklarına iyi bir rehberlik yapabilmeleri için dijital okuryazarlık becerilerini geliştirmeleri gerektiği sonucuna ulaşmıştır. Baştürk Akca, Sayımer, Balaban Salı ve Ergün Başak (2014) yaptıkları araştırmada dijital teknoloji okuryazarlığı için bireylerin bazı becerilere sahip olması gerektiği ve siber zorbalık gibi tehlikelerden korunmak için bireylerin dijital okuryazar olması gerektiği sonucuna ulaşmışlardır. Arabacı ve Polat (2013) yaptıkları araştırmada teknoloji okuryazarlığının öğrenciler arasında düşük öğretmenler arasında ise orta seviyede olduğu sonucuna ulaşmışlardır. Araştırmada öğretmenlerin öğrencilere kaliteli ve nitelikli bir eğitim sunmaları için teknoloji okuryazarlık düzeylerinin iyi derecede olması gerektiği ifade edilmiştir. Ancak erken çocuklukta dijital materyaller olmaması gerektiğini ifade eden öğretmenler olmuştur. Benzer olarak Aldhafeeri, Palaiologou \& Folorunsho (2016) yaptıkları araştırmada öğretmenlerin sınıflarında teknolojik alet kullanmamaları ve çocukları dijital aletlerden uzak tutmalarının sebebi öğretmenlerin bilgi ya da kaynak eksikliğinden değil tamamen ön yargı ve teknolojiye karşı olumsuz tutumlarından kaynaklandığı sonucuna ulaşmışlardır. Ancak Ata ve Yıldıım (2016) yaptıkları araştırmada öğretmen adaylarının dijital okuryazarlığa ilişkin farkındalıklarının olduğu ancak yetkinliklerinin sınırlı olduğu sonucuna ulaşmışlardır. Araştırmalar arasındaki 
bu farklııı dijital araçların eğitimde kullanılması konusunda sahip olunan kaynak, yetkinlik ve görüş farklılığından kaynaklanabilir. Dijital okuryazarlığın doğru bilgiye kısa sürede ulaşma, öğrenmeyi kolaylaştırma, teknolojik araçlara yönelik farkındalık kazandırma, teknolojiyi doğru kullanma açısından faydalı olduğu ifade edilmiştir. Flewitt, Messer \& Kucirkova (2015) yaptıkları araştırmada okul öncesi eğitim sınıflarında I pad kullanımının çocukların okuryazarlık becerileri geliştirdiği ayrıca çocukların hem bireysel hem de işbirlikli öğrenme süreçlerine katkıda bulunduğu sonucuna ulaşmışlardır. Kumpulainen \& Gillen (2019) yaptıkları araştırmada ailelerin her zaman çocuklarının online etkinlikleri ve dijital araçlarla geçirdikleri zamanın farkında olmadıkları sonucuna ulaşmışlardır. Ayrıca ailelerin dijital aletlerin içerdiği risklerden çok faydalarına odaklandığı sonucu çıkmıştır. Dolayısıyla dijital okuryazarlık becerisi, dijital araçların sadece faydalarının değil içerdiği risklerinde farkında olunması açısından önemlidir. Çocuğun doğru teknoloji kullanımı için sosyal etkinliklere yönlendirilmesi, teknoloji kullanımını sınırlandırma, ebeveynle kullanım ve içerik denetimi gibi öneriler gelmiştir. Benzer olarak Mustafaoğlu, Zirek, Yasacı \& Özdinçler (2018) çocukların dijital alet kullanımının sağlıklı olması için onları besleyen bir sosyal çevrenin olması gerektiğini ifade etmişlerdir. Ayrıca Muslu ve Bolışık (2009) yaptıkları araştırmada çocukların internet kullanımı konusunda bilgilendirilmeleri ve takip edilmeleri gerektiğini ifade etmişlerdir.

Sonuç olarak okul öncesi öğretmenleri dijital okuryazarlığın faydalı olduğu, çocuğun gelişimine katkıda bulunduğu, dijital okuryazarlık eğitimlerinin verilmesi gerektiğini ifade etmiştir. Dijital materyallerin okul öncesi eğitimde olmaması gerektiğini ifade eden öğretmenler de olmuştur. Güvenli dijital alet kullanımı için çocuklara sosyal çevre oluşturulması gerektiği, içerik denetimlerinin arttırılması, çocukla oyun oynama ve çocukla kitap okuma gerektiği ifade edilmiştir.

Öneri olarak dijital çağda bilginin daha güvenilir, kolay ve hızlı elde edilmesi için çocuklara, öğretmenlere ve ailelere dijital okuryazarlık eğitimi verilmesi önerilebilir. Bununla birlikte çocuğun teknoloji bağımlısı olması ve bundan doğacak zararlardan kaçınılması için çocuğa nitelikli bir sosyal çevrenin sunulması, teknoloji kullanımında rehberlik edilmesi ve teknoloji kullanımında içerik denetimlerinin arttırılması önerilebilir.

\section{Çıkar Çatışması Bildirimi}

Yazar, bu makalenin araştırılması, yazarlığı ve / veya yayınlanmasına ilişkin herhangi bir potansiyel çıkar çatışması beyan etmemiştir.

\section{Destek/Finansman Bilgileri}

Yazar, bu makalenin araştırılması, yazarlığı ve / veya yayınlanması için herhangi bir finansal destek almamıştır.

\section{Etik Kurul Kararı}

Bu araştırmanın verileri 2020 yılı tarihinden önce toplandığı ve araştırmanın yayınlanması için 01.01.2020 tarihinden önce dergiye başvuruda bulunulduğu için etik izin beyan edilmemiştir.

\section{KAYNAKÇA/REFERENCES}

Acar, Ç. Y. (2015). Anne ve babaların ilkokul ortaokul ve lise öğrencisi çocukları ile kendilerinin dijital okuryazarlıklarına ilişkin görüşleri. Yayınlanmamış Yüksek Lisans Tezi. Ankara Üniversitesi Eğitim Bilimleri Enstitüsü, Ankara.

Aldhafeeri, F., Palaiologou, I., \& Folorunsho, A. (2016). Integration of digital technologies into play-based pedagogy in Kuwaiti early childhood education: Teachers' views, attitudes and aptitudes. International Journal of Early Years Education, 24(3), 342-360.

Arabacı, İ. B., \& Polat, M. (2013). Dijital yerliler, dijital göçmenler ve sınıf yönetimi. Elektronik Sosyal Bilimler Dergisi, 12(47), 11-20.

Ata, R., \& Yıldırım, K. (2016). Öğretmen Adaylarının Medya Okuryazarlığı Dersi Kapsamında İnternet ve Sosyal Medya Kullanımları. Journal of Kirsehir Education Faculty, 17(2), 581-602. 
Avcı, A. (2010). Aile yapı ve atmosferinin okul şiddetine etkisi. Değerler Eğitimi Dergisi, 8(19), 7-52.

Baştürk Akca, E., Sayımer, I.., Balaban Salı, J., \& Ergün Başak, B. (2014). Okulda siber zorbalığın nedenleri, türleri ve medya okuryazarlığı eğitiminin önleyici çalışmalardaki yeri. Elektronik Mesleki Gelişim ve Araştırma Dergisi, 2(özel sayı), 17-30.

Buckingham, D., Banaji, S., Carr, D., Cranmer, S., \& Willett, R. (2005). The media literacy of children and young people: A review of the research literature. Centre for the Study of Children Youth and Media Institute of Education University of London

Büyükbaykal, G. (2007). Televizyonun çocuklar üzerindeki etkileri. İstanbul Üniversitesi Iletişim Fakültesi Dergisi, Istanbul University Faculty of Communication Journal, (28), 31-44.

Cantor, J., \& Wilson, B. J. (2003). Media and violence: Intervention strategies for reducing aggression. Media Psychology, 5(4), 363-403.

Coşkun, Y., \& Arslantaş, H. (2016). Okul Öncesi Eğitime Devam Eden Çocukların Televizyon İzlemelerine Yönelik Anne Görüşlerinin İncelenmesi. Kahramanmaraş Sütçü Imam Üniversitesi Sosyal Bilimler Dergisi, 13(2), 1-16.

Curran, C., \& Hyman, M. R. (2000). Children and Advertising: The Influence of Cognitive Development Models on Research Questions and Results. Working paper. https://www.researchgate.net/publication/259197434_Children_and_advertising_The_influence_of_c ognitive development models on research questions and results $W$ orking Paper adresinden 20.12.2019 tarihinde erişim sağlanmıştır.

Doğan, A., \& Göker, G. (2012). Tematik televizyon ve çocuk: ilköğretim öğrencilerinin televizyon izleme alışkanlıkları. Milli Eğitim Dergisi, 42(194), 5-30.

Donohue, C. (2014). Technology and digital media as tools for teaching and learning in the digital age. In Technology and Digital Media in the Early Years (pp. 53-67). Routledge.

Donnerstein, E., \& Linz, D. (1986). Mass media sexual violence and male viewers: Current theory and research. American Behavioral Scientist, 29(5), 601-618.

Flewitt, R., Messer, D., \& Kucirkova, N. (2015). New directions for early literacy in a digital age: The iPad. Journal of Early Childhood Literacy, 15(3), 289-310.

Gigli, S. (2004). Children, youth and media around the world: An overview of trends \& issues. [Conference presentation]. 4th World Summit on Media for Children and Adolescents. Rio de Janeiro, Brazil.

Gillen, J., Arnott, L., Marsh, J., Bus, A., Castro, T., Dardanou, M.,... \& Holloway, D. (2018). Digital Literacy and young children: towards better understandings of the benefits and challenges of digital technologies in homes and early years settings. Policy briefing of DigiLitEY COST Action IS1410 and the Digital Childhoods SIG of the European Early Childhood Research Association.

Gillen, J., \& Kucirkova, N. (2017). Literacy learning in a digital world. European Early Childhood Research Association https://core.ac.uk/reader/158169730 adresinden 20.12.2019 tarihinde erişim sağlanmıştır.

Hamutoğlu, N. B., Güngören, Ö. C., Uyanık, G. K., \& Erdoğan, D. G. (2017). Dijital okuryazarlık ölçeği: Türkçe'ye uyarlama çalışması. Ege Eğitim Dergisi, 18(1), 408-429.

Ihmeideh, F., \& Alkhawaldeh, M. (2017). Teachers' and parents' perceptions of the role of technology and digital media in developing child culture in the early years. Children and Youth Services Review, 77, 139-146.

Jolin, E. M., \& Weller, R. A. (2011). Television viewing and its impact on childhood behaviors. Current psychiatry reports, 13(2), 122-128.

Karabacak, Z. İ., ve Sezgin, A. A. (2019). Türkiye'de Dijital Dönüşüm Ve Dijital Okuryazarlık. Türk Iddare Dergisi, 91(288), 319-343.

Koçyiğit, S., Gündoğdu,K \& Bay, E. (2010). Okul öncesi öğretmen adaylarının okulda şiddetin kaynağı üzerine algıları, Mediterranean Journal of Educational Research, 7, 41-59.

Kumpulainen, K., \& Gillen, J. (2019). Young Children's Digital Literacy Practices in the Home. The Routledge Handbook of Digital Literacies in Early Childhood, 95, 1-34.

Kuula, T., Kuusisto, O., \& Seisto, A. (2014). The Development of Media Use Habits-from Childhood to Adults. In 41st International Research Conference of IARIGAI (pp. 129-132). IARIGAI-International Association of Research Organizations for the Printing, Information and Communication Industries.

Livingstone, S. (2007). On the material and the symbolic: Silverstone's double articulation of research traditions in new media studies. New media \& society, 9(1), 16-24.

Marsh, J. A. (2016). The digital literacy skills and competences of children of pre-school age. Media Education: Studi, Ricerche, Buone Practice, 7(2), 197-214.

Muslu, G. K., \& Bolışık, B. (2009). Çocuk ve Gençlerde İnternet Kullanımı. TAF Preventive Medicine Bulletin, 8(5), 445-450. 
Mustafaoğlu, R., Zirek, E., Yasacı, Z., \& Özdinçler, A. R. (2018). Dijital teknoloji kullanımının çocukların gelişimi ve sağlığı üzerine olumsuz etkileri. Addicta: The Turkish Journal on Addictions, 5(2), 1-21.

Nathanson, A. I., \& Cantor, J. (2000). Reducing the aggression-promoting effect of violent cartoons by increasing children's fictional involvement with the victim: A study of active mediation. Journal of Broadcasting \& Electronic Media, 44(1), 125-142.

Ocak, G. ve Karakuş, G. (2018). Öğretmen Adaylarının Dijital Okuryazarlık Öz-Yeterliliği Ölçek Geliştirme Çalışması. Kastamonu Eğitim Dergisi, 26(5), 1427-1436.

O'Keeffe, G. S., \& Clarke-Pearson, K. (2011). The impact of social media on children, adolescents, and families. Pediatrics, 127(4), 800-804.

Onursoy, S. (2018). Üniversite Gençliğinin Dijital Okuryazarlık Düzeyleri: Anadolu Üniversitesi Öğrencileri Üzerine Bir Araştırma. Gümüşhane Üniversitesi Iletişim Fakültesi Elektronik Dergisi, 6(2), 989-1013.

Özerbaş, M. A., \& Kuralbayeva, A. (2018). Türkiye ve Kazakistan Öğretmen Adaylarının Dijital Okuryazarlık Düzeylerinin Değerlendirilmesi. Muğla Sıtkı Koçman Üniversitesi Eğitim Fakültesi Dergisi, 5(1), 16-25.

Patton, M. Q. (2014). Qualitative research \& evaluation methods: Integrating theory and practice (4th ed.). Thousand Oaks, CA: Sage.

Peterson, J., \& Densley, J. (2017). Cyber violence: What do we know and where do we go from here?. Aggression and violent behavior, 34, 193-200.

Potter, W. J. (2013). Review of literature on media literacy. Sociology Compass, 7(6), 417-435.

Tahiroğlu, A. Y., Çelik, G. G., Bahalı, K., \& Avcı, A. (2010). Medyanın Çocuk ve Gençler Üzerine Olumsuz Etkileri; Şiddet Eğilimi ve İnternet Bağımlığı. Yeni Symposium journal, 48(1), 19-30.

Temel, M., Kostak, M. A., \& Çelikkalp, Ü. (2014). Çocuk kanallarında yayınlanan çizgi filmlerdeki şiddetin belirlenmesi. Dokuz Eylül Üniversitesi Hemşirelik Fakültesi Elektronik Dergisi, 7(3), 199-205.

Üstündağ, M. T., Güneş, E., \& Bahçivan, E. (2017). Dijital okuryazarlık ölçeğinin türkçeye uyarlanması ve fen bilgisi öğretmen adaylarının dijital okuryazarlık durumları. Journal of Education and Future, 12, 19-29.

VanderBorght, M., \& Jaswal, V. K. (2009). Who knows best? Preschoolers sometimes prefer child informants over adult informants. Infant and Child Development: An International Journal of Research and Practice, 18(1), 61-71.

Villani, S. (2001). Impact of media on children and adolescents: a 10-year review of the research. Journal of the American Academy of child \& adolescent psychiatry, 40(4), 392-401.

Yıldırım, A., \& Şimşek, H. (2013). Sosyal Bilimlerde Nitel Araştırma Yöntemleri, Seçkin Yayıncılık, Ankara.

İletișim/Correspondence

Dr. Öğr. Üyesi Servet KARDEŞ

kardesservet@gmail.com 